\title{
MEMÓRIAS E CONSTRUÇÃo DE NARRATIVAS DAS RÁDIOS OCIDENTAIS SOBRE ÁFRICA
}

\author{
Celestino Joanguete \\ Departamento de Comunicação, Escola de Comunicação e Artes, Universidade Eduardo Mondlane, Moçambique
}

\begin{abstract}
ReSUMo
Três marcos históricos permitem uma reflexão sobre as narrativas das rádios transnacionais em África: a expansão de canais transnacionais em África, depois da II Guerra Mundial e o início da Guerra Fria; a realização da "Conferência dos países não alinhados" em Bandung, 1955, que expressava a vontade de soberania dos países da África e Ásia; o "Fórum de meios de comunicação social e desenvolvimento" (2008) realizado em Uagadugu, Burquina Faso, que manifestava a vontade de "descolonização da informação". Estes grandes acontecimentos despertaram um certo interesse no campo dos Estudos da Rádio na África. A presente reflexão tem como objetivo analisar as narrativas das rádios ocidentais em África, concentrando-se na revisão histórica do papel da rádio como meio de expansão do imperialismo ocidental. Numa outra perspetiva, a reflexão tenta capturar as últimas tendências de mudanças ideológicas e discursivas das rádios internacionais em África: a internacionalização comparticipada, a promoção de consciência de democracia e o despertar de direitos humanos. A emergência das novas narrativas das rádios africanas, mediadas por web rádios nas plataformas das redes sociais da internet e as suas potencialidades, constituem outros pontos de reflexão. Numa análise desta informação histórica, o estudo optou por uma abordagem de natureza interpretativa da documentação, declarações de conferências e literatura produzida sobre as rádios internacionais em África, naquilo que se aproxima da análise tipológica desenvolvida pelo sociólogo Max Weber sobre os tipos ideais, ou seja, uma hermenêutica de cunho interpretativo e explicativo, na qual se deve compreender textos, ideologias, culturas e períodos históricos como símbolos que devem ser elucidados dentro de seus próprios sistemas de significação. Este modelo de análise extrai do material bibliográfico os elementos típicos e descreve-os com detalhe.
\end{abstract}

\section{WESTERN RADIO MEMORIES AND NARRATIVE CONSTRUCtion on Africa}

\begin{abstract}
Three historical milestones allow a reflection on the narratives of transnational radio stations in Africa: the expansion of transnational channels in Africa, after the Second World War and the beginning of the Cold War; the holding of the "Conference of non-aligned countries" in Bandung, 1955, which expressed the will of sovereignty of the countries of Africa and Asia; the "Media and development forum" held in Ouagadougou, Burkina Faso, which expressed the desire to "decolonize information". These great events aroused a certain interest in the field of Radio Studies in Africa. The present reflection aims to analyze the narratives of Western radio stations in Africa, which it focuses on the historical review of the role of radio as a mean of expanding Western imperialism. From a different perspective, the reflection tries to capture the
\end{abstract}




\begin{abstract}
latest trends in ideological and discursive changes in international radio in Africa: internationalized participation, the promotion of democracy awareness, and the awakening of human rights. The emergence of the new narratives of Africans radio stations, mediated by web radios on the platforms of social networks on the internet and their potential, are other points of reflection. In an analysis of this historical information, the study opted for an interpretative approach to the documentation, conference statements, and literature produced on international radio in Africa, what comes close to the topological analysis developed by sociologist Max Weber on the ideal types, an interpretative and explanatory hermeneutic, in which texts, ideologies, culture and historical periods must be understood as symbols that must be elucidated within their systems of signification. This analysis model extracts typical elements from the bibliographic material and describes them in detail.
\end{abstract}

\title{
KEYwORDS
}

radio; imperialism; social networks

\section{INTRODUÇÃo}

A memória é uma função cognitiva construída por um indivíduo, organizações ou pela sociedade para armazenar e transmitir informações através da expressão escrita, oral e eletrónica. Um percurso pela memória da literatura e documentação sobre as rádios transnacionais em África permitiu a elaboração do presente artigo. O objetivo é compreender a construção de narrativas das rádios internacionais em África. Por um lado, para um melhor entendimento das suas ideologias em África, por outro, para compreender o processo da "descolonização da informação" e o subsequente papel assumido pelas rádios africanas nas sociedades independentes, suas implicações políticas e culturais, sua contribuição efetiva para o desenvolvimento de democracia e cidadania e, por último, compreender os desafios das rádios africanas na era digital.

O problema das rádios ocidentais quer no período da colonização ocidental, caracterizado pelo imperialismo ideológico e cultural, quer na era pós-colonial, caracterizada pelas mudanças das narrativas de transmissão de informação, apresenta pouca profundidade epistemológica e histórica nos anais da história da rádio em África. Nesta reflexão, as questões centrais são: que tipo de narrativas foram produzidas pelas rádios transnacionais sobre África nos períodos da colonização e depois das independências? Que perspectivas para o futuro da rádio em África?

Três aspetos respondem à primeira pergunta de partida nesta reflexão: o plano histórico e teórico que contribuiu para a construção de narrativas ideológicas das rádios ocidentais em África; a perceção dos africanos sobre as narrativas das rádios ocidentais, com base nos relatos e estudos teóricos dos académicos africanos e escritores; por fim, a abertura da África ao mundo, graças aos meios alternativos de comunicação, baseada nas redes sociais da internet e a possibilidade de construção das suas próprias narrativas desintermediadas.

A evolução dos estudos de rádio pode ser analisada em duas abordagens: ou por uma abordagem epistemológica, buscando em quais campos de pesquisa surgiram 
esses estudos, como eles foram integrados em Estudos da Comunicação de Massa ou por uma abordagem histórica, apresentando a evolução da própria rádio, ambiente social e cultural que se estabeleceu. É a segunda postura que o presente estudo optou por privilegiar e refazer a rota descrita pelos estudos anteriores.

A diversidade de bibliografia e temas sobre as rádios em África exigiu um esforço de agrupar diferentes fontes de informação, seguida de uma análise interpretativa da informação. Por último, a discussão de resultados foi um exercício que tentou estabelecer um confronto dialético entre os autores e mostrou a relação entre os conceitos expostos e a questão central de estudo.

As análises dos resultados do estudo permitiram concluir que a expansão das rádios transnacionais em África e as respectivas narrativas foram impulsionadas por três interesses históricos e ideológicos: primeiro, pela manutenção dos valores culturais e da civilização ocidental durante e depois do período colonial; segundo, pelas guerras ideológicas durante o período da Guerra Fria, altura da massificação das rádios ocidentais no continente africano devido à bipolarização antagónica entre os blocos capitalista e comunista; e o terceiro interesse, depois da Guerra Fria, era o do desenvolvimento da cooperação e de produção de novas narrativas focalizadas em regiões de conflitos em África.

\section{Contextualização}

A presente reflexão inspira-se nas publicações de Asante (2013) sobre "The Western media and the falsification of Africa: complications of value and evaluation", da corrente de pensamento latino-americana sobre imperialismo cultural, e nos estudos de Biney (1997) sobre "The Western media and Africa: issues of information and images" no Journal of International Affairs, publicações que desconstruiram as ideologias dos média ocidentais em África.

As audiências ocidentais, ao longo de muitos anos, construíram a imagem de África como sendo um lugar de caos, conflitos tribais, guerras étnicas, corrupção, doenças e genocídios. De facto, são construções sociais levadas a cabo pelo poder dos média num continente imenso e de diversidade cultural. Porém, tem havido poucos esforços dos mesmos em apresentar os aspetos positivos do continente africano como, por exemplo, o empreendedorismo africano, as invenções, o desenvolvimento do campo da educação, a riqueza cultural e outras dinâmicas sociais.

A rádio foi um dos meios de comunicação social de dominação imperialista em África. Para Power (2000), por exemplo, durante o período de colonização de Moçambique, representava seu trabalho como sendo uma rádio de colonização que enfatizava os vínculos entre as suas atividades e a manutenção da cultura e civilização europeia nas colónias. Em Moçambique, ela procurava solidificar a sua contribuiç̧ão para a cultura e civilização ocidental em função dos objetivos políticos coloniais.

Nos últimos dias do colonialismo português, as emissoras começaram tardiamente a tentar assimilar assuntos não-brancos na ordem percebida de modernização 
colonial. A programação da rádio foi diferenciada de maneiras importantes de acordo com a etnia e o género (Power, 2000).

Em todo o continente africano, a rádio apresentou um passo importante na conquista dos outros territórios, graças à sua facilidade de propagação pelo ar, através das ondas hertzianas, sobretudo durante o período conturbado da II Guerra Mundial.

Após a II Guerra Mundial, foram realizadas conferências internacionais sobre os aspetos técnicos de regulação, especificamente a atribuição de frequência de transmissão. A primeira conferência realizou-se em Moscovo, em setembro de 1946. A segunda foi em Atlantic City, nos EUA, ambas deram origem ao Comité Internacional de Registo de Frequência (Jeanneney, 1996, p. 267).

$\mathrm{Na}$ "World Administrative Radio Conference" realizada em Genebra, 1979, sob a égide da União Internacional das Telecomunicações (UIT), os americanos tentaram, sem sucesso, opor-se à redistribuição da frequência de transmissão da rádio, praticamente monopolizada por eles e outros países industrializados, em detrimento dos países em vias de desenvolvimento, o que indicava uma tentativa de monopolizar as frequências e impor a superioridade técnica e ideológica naquilo que lhes caracteriza nas teorias de comunicação de massa (Joanguete, 2010).

Foi notável durante a Guerra Fria, os países capitalistas e socialistas competirem pelo poder de controlo de informação. Cada vez mais ficava claro que se tratava de uma guerra ideológica. De um lado, os EUA propagavam a seu favor a ideologia da cultura de massas, através de suas músicas e da indústria cinematográfica. Por outro, a história das relações entre os vários países do Leste europeu e os países do continente africano, que adotaram modelos socialistas durante as guerras para a libertação nacional, como também no período pós-independência, não se preocupava com ideologias, mas antes em garantir ajuda financeira e militar dos países comunistas do Leste para derrubar a dominação colonial do Ocidente (Cascais \& Blanchard, 2017; Groppo, 2008).

Groppo (2008, pp. 131-132) afirma que:

a ligação que se instaurou entre os partidos comunistas e a URSS não era simplesmente de dependência política, mas também de dependência material. Muitos desses partidos recebiam do Estado soviético, de forma direta ou indireta, financiamentos e diversos tipos de ajuda, mais ou menos consistentes, dos quais dependia, em parte, a capacidade deles de desenvolver uma atividade política constante.

No continente africano, a relação de cooperação entre os países comunistas do Leste e os que seguiam o regime comunista incluía a abertura de espaço para a retransmissão de rádios da URSS. O cenário manteve-se mesmo depois da independência dos países africanos, pois muitas potências ocidentais trataram de introduzir uma lógica de monopólio do sinal de transmissão de rádios e sua internacionalização (Mattelart \& Mattelart, 1997). Neste quadro, algumas academias e centros de pesquisa em comunicação começaram a preocupar-se com as ideias propagandísticas e com a disputa pela dominação cultural e ideológica. 
Num artigo publicano por Barrot (2010) na La revue des médias intitulado "Les radios internationales en Afrique", o autor afirma que nenhuma outra região do planeta é tão aberta a informações internacionais e tão dependente de emissoras estrangeiras como a África Subsaariana. Entre as rádios internacionais ouvidas na África, alinham-se centenas de transmissores internacionais no continente como os da British Broadcasting Corporation (BBC) World Service, Voice of America (VOA) e, recentemente, a rádio Chine Internationale.

A escola francesa de comunicação, conhecida pelas teorias culturalistas, questionou a maneira como se procedia à internacionalização dos meios de comunicação ocidentais e como interferiam de forma direta na cultura dos outros povos com os aparelhos ideológicos de Estado, como a rádio e televisão ou as indústrias culturais imperialistas (Mattelart \& Mattelart, 1997).

O historiador britânico Trevor-Roper (1969) escrevia no seu artigo "The past and the present: History and Sociology", que em África não havia nenhuma história a contar, apenas a história dos europeus na África. O mesmo discurso do historiador reproduziu-se implicitamente nas políticas dos média quando começou a corrida pelas novas audiências africanas.

Devemos entender que todos os relatos apresentados sobre a rádio em África configuram-se como mecanismo ideológico de controlo de massas africanas, que ao longo da história foram ganhando outras significações, quer nos aspetos técnicos, quer ideológicos.

\section{As RÁDIOS NACIONAIS PÓS-INDEPENDÊNCIAS}

$\mathrm{Na}$ sociedade colonial, em que a rádio imperava como meio de comunicação de massa, é preciso encarar a cultura como um meio carregado de ideologia. Depois das independências dos países africanos, a partir da década de 60 , as rádios eram um meio de comunicação de massa do monopólio estatal e seguiam as linhas orientadoras dos governos e não podiam transmitir conteúdos que suscitassem outras mudanças políticas dentro de suas próprias populações. A informação era muito controlada (Agbobli, 2016; Perret, 2010).

Myers (2008) e Ilboudo (2014) relatam que depois da independência, a maioria das transmissões das rádio nacionais foram estabelecidas. Passaram a emitir na língua do ex-colonizador e, às vezes, em uma ou duas línguas nacionais para afirmar o papel de novos estados independentes e, neste contexto, a rádio tornou-se um atributo de independência desses países e os serviços de rádios controlados pelos estados independentes conquistaram as maiores audiências na maior parte da África Subsaariana.

Convém dizer que a primeira manifestação de autonomia africana no sector das telecomunicações e audiovisual foi a criação, em 1962, da Union des Radiodiffusions and Televisions Nationales d'Afrique (URTNA), composta pelas organizações nacionais de rádio e televisão dos estados africanos. Mais tarde, a URTNA foi transformada no dia 30 de outubro de 2006 em União Africana de Radiodifusão (AUB), com o objetivo 
de contribuir para enriquecer a qualidade de vida dos africanos e revelar uma verdadeira imagem da África.

Como se pode notar, a URTNA é o primeiro organismo africano que busca resgatar a imagem de África, através de produção e distribuição de conteúdos produzidos pelos africanos. Contudo, a URTNA estava longe de debater a regulação dos média e os aspetos políticos da comunicação. As principais preocupações estavam concentradas na construção da nação através dos média. Nisto, os governos assumiram o controlo das rádios para a construção da nação, facilitou a tarefa dos governos na educação do povo e elevou a consciência nacional. Os média eram um catalisador de políticas governamentais; unificar a nação e popularizar os líderes dos governos (Asante, 2013).

Apesar da nacionalização das rádios do regime colonial, a África Subsaariana foi, desde o início da independência e da Guerra Fria, o foco de transmissões em ondas curtas em várias línguas por emissoras transnacionais, concretamente das antigas potências coloniais e dos principais países comunistas. Por exemplo, em 1958 e 1959, a Rádio Moscovo e a Rádio Pequim lançaram suas emissões em Francês, Inglês e Português para o continente africano (Mattelart, 2015).

A "Conferência dos países não alinhados" realizada em Bandung, Indonésia, em 1955, era o primeiro marco político que expressava a vontade de soberania dos países da África e da Ásia. Era o primeiro movimento a favor do renascimento africano, inclusive asiático, no campo da economia, política e no sector dos média. Graças a essa organização dos países não alinhados contra o colonialismo, as políticas públicas de comunicação abriram o espaço para a globalização neoliberal, da qual resultou um desequilíbrio nos processos comunicativos (Amin, 2015).

Na mesma sequência, em 1970 foi lançado o debate sobre a Nova Ordem Mundial da Informação e Comunicação (NOMIC), um projeto internacional de reorganização dos fluxos globais de informação, por meio de diversas ações de governos. A NOMIC foi uma iniciativa do movimento dos países não alinhados e com apoio da Unesco, cujo objetivo era a "descolonização no domínio da Informação" (Silva, 2009, p. 11).

A descolonização da informação era um debate dos finais da década de 6o. No entender de Bourges (1978) a rede mundial de informações estava nas mãos dos países ricos, enquanto os países em desenvolvimento não tinham o lugar que deveria ser deles. A prova disso é que as grandes agências de notícias, europeias e americanas, produziam e distribuíam a matéria-prima das notícias publicadas em todo o mundo. Daí a necessidade de implementar, em escala mundial, uma política que reduzisse a hegemonia das grandes potências.

Outro marco importante na história dos média em África foi a realização da "Conferência geral de Nairobi", 1976, organizada pela Unesco, que constituiu uma comissão internacional para o estudo do fluxo mundial de comunicação. A comissão era presidida pelo jornalista, jurista e ex-ministro das relações exteriores da Irlanda, Seán MacBride, composta por 16 personalidades internacionais da área da cultura e da comunicação. Esta comissão trabalhou até 1980, quando elaborou e divulgou um relatório com o título de Um mundo e muitas vozes, mas que ficou também conhecido como Relatório 
MacBride, no qual relatava os desequilíbrios comunicacionais no mundo e a predominância de narrativas únicas nos média ocidentais (Silva, 2009).

Internamente, no continente africano, as conferências internacionais para discutir o relatório de MacBride sobre o fluxo de informação equilibrado e o impacto das rádios e televisões ocidentais em África constituiu tema de agenda no "Fórum de meios de comunicação social e desenvolvimento" realizado em Uagadugu, Burquina Faso, nos dias 11 a 13 de setembro de 2008, organizado pela Comissão Europeia, Comissão da União Africana, Organização Internacional da Francofonia, Comunidade Britânica e a Comunidade dos Países da Língua Portuguesa, que constituíram os primeiros debates internacionais sobre a nova dinâmica de comunicação social em África.

Particularmente nas ex-colónias portuguesas, a preocupação de estabelecer uma rádio que ligasse as colónias e a metrópole já remontava aos anos de 1935. Porém, a ideia só veio a materializar-se 60 anos depois, com a criação da RDP África em abril de 1996, pelo Despacho n. 25 356/2006, Diário da República, 2. ${ }^{a}$ Série, n. ${ }^{\circ}$ 238, 13 de dezembro de 2006, num contexto de regime político diferente, tendo como base ideológica a difusão da língua e cultura portuguesa e "trazendo para Portugal uma larga informação africana" (Jordão, 2009, p. 19).

Contra os estereótipos ocidentais sobre África, realizou-se em setembro de 2008 no Burquina Faso o "Fórum de meios de comunicação social e desenvolvimento", que permitiu colocar à luz o debate sobre o assunto. Para Jean-Luc Maertens, diretor da Euronews que presidiu a mesa redonda sobre os estereótipos de África na Europa e os da Europa em África, concluiu que muitos destes problemas devem-se, em grande parte, aos meios de comunicação ocidentais e sobre os quais deveriam ser instituídas certas medidas para atenuar os impactos, tal como uma forte pressão em determinados média que os veiculam e apoiam (Goutier, 2008).

Em síntese, nota-se neste quadro histórico que as administrações coloniais usaram a rádio como uma ferramenta política para preservar o domínio colonial e impor a cultura ocidental. Contrariamente, os líderes africanos pós-independência usaram a rádio para promover a construção da nação, sobretudo, transformaram a rádio num meio de mobilização para a solidificação do estado-nação.

No entanto, na década de 90 , a situação mudou quase drasticamente à medida que avançavam os regimes democráticos em África e, consequentemente, os média ganhavam a liberdade de imprensa e de expressão. A pesquisa feita pela African Media Development Initiative (AMDI), em 17 países subsaarianos, descobriu que as rádios comerciais locais cresceram em média $360 \%$ entre 2000 e 2006 e as rádios comunitárias cresceram em média 1,386\% em relação ao mesmo período (Myers, 2008).

\section{AS IDEOLOGIAS NAS NARRATIVAS DAS RÁDIOS OCIDENTAIS}

As primeiras transmissões de rádio na África Subsaariana foram feitas no início dos anos 1920. O Quênia tinha sua própria estação de rádio em 1927, seguida por 
Moçambique em 1933 e o Senegal em 1939. Mas estas rádios tinham programas que eram transmitidos para a população europeia em África'.

O desenvolvimento das comunicações via satélite possibilitou que as tradicionais emissões internacionais em ondas curtas, promovidas principalmente por estações estatais e públicas ocidentais, fossem também retransmitidas por estações de rádios em África em ondas curtas e ondas médias, porque a maioria da população africana vivia em zonas rurais e muito dispersas. Para longas distâncias, usavam-se emissores de ondas curtas. Para as cidades, usavam-se emissores de ondas médias.

Depois da II Guerra Mundial, a República Federal da Alemanha marca a sua presença em África através da rádio Deutsche Welle (DW); a Grã- Bretanha com a British Broadcasting Corporation (BBC); a Holanda através da Rádio Nederland, a França com a Rádio França Internacional (RFI); os Estados Unidos com a Voice of America (VOA). Todas estavam entre as estações das rádios mais ouvidas no mundo e em África (Jeanneney, 1996).

Comparativamente, a atuação política francesa de comunicação internacional em África foi facilitada pelas suas relações de afinidade com as ex-colónias, desde os tempos da Rádio Paris Mondial. A RFI agora tem 107 transmissores FM no continente, todos localizados na África subsaariana, incluindo 82 na África francófona, onde sua participação de mercado chega a 25\% (Barrot, 2010). Enquanto isso, a política de comunicação internacional da BBC estava focalizada para audiência da Índia, mais tarde houve mudança para audiência mundial, incluindo África com 70 transmissores FM em África, transmitindo em Inglês para 36 países (Barrot, 2010; Jeanneney, 1996). Por isso, a BBC é considerada a estação de maior audiência, que ronda em volta de 120 milhões de ouvintes em todo o mundo. Este número não inclui países como a China, onde estudos de audiência não foram feitos por questões políticas (Sousa, 1993).

A prática de retransmissão das rádios e televisões internacionais em África é baseada em acordos comerciais de venda de espaços, cenário que criou uma lógica de penetração no continente africano. A mesma política era praticada pela URSS durante a Guerra Fria na década de 6o. Por exemplo, a VOA foi fundada no dia quatro de agosto de 1963 para fornecer serviços de notícia para África. Contudo, a ideologia subjacente na VOA é de combater os regimes não-democráticos, promovendo os direitos humanos e as liberdades em África, oferecendo serviços noticiosos mais abertos e sem censura a mais de 25 milhões de ouvintes.

Landau (2012) afirma que as mutações das narrativas das rádios ocidentais sobre África ganham uma nova abordagem mais africanista a partir dos finais dos anos 60 e início da década de 70, quando os países francófonos desencadearam uma série de reivindicações de direitos junto da RFI, que detinha o monopólio do mercado francófono.

As mudanças da Rádio e Televisão Portuguesa (RTP) ocorreram nos países africanos falantes da língua portuguesa através de acordos de cooperação técnica para o domínio da comunicação social em três campos: (a) a assistência técnica; (b) a formação 
profissional; (c) o intercâmbio e a circulação de jornalistas e a circulação de informação (Carvalho, 1994; Jordão, 2009).

Na sequência desta cooperação, entre 1987 e 1989, foram estabelecidos acordos entre a Radiodifusão Portuguesa (RDP) e as rádios nacionais dos países africanos falantes da língua portuguesa (PALOP), bem como entre a Agência de Notícias de Portugal (Anop) posteriormente, Lusa - e as agências noticiosas das ex-colónias portuguesas.

Para integrar as narrativas africanas nas suas programações, a RDP África estruturou a sua equipa redatorial e de correspondentes, compondo-a por 36 elementos, entre jornalistas e realizadores de nacionalidade portuguesa e dos países africanos de expressão portuguesa, cujo trabalho tem o propósito de funcionar de forma bilateral, África/ Portugal e trazendo para Portugal uma larga informação africana (Jordão, 2009, p. 19).

Paralelamente, a BBC disputa a mesma audiência com a RTP em serviços da língua portuguesa. O serviço português da BBC consegue metade da audiência de todas as rádios internacionais a retransmitir para os PALOP, graças a 80 estações de retransmissão de radiodifusão em onda curta situadas nas Ilha de Ascensão, Ilhas das Maurícias, Seicheles, Lesoto, África do Sul e Madagáscar. Deste modo, as transmissões vindas do Reino Unido chegavam a África, incluindo aos países menos democráticos com leis rígidas que impediam a presença dos órgãos de comunicação estrangeiros.

Nos anos 90, a BBC mudou da sua tradicional estratégia de transmissão em ondas curtas para FM de duas formas: através de seu próprio relé de 24 horas numa frequência dedicada ou através de acordos de retransmissão com estações de rádio locais. É nisto que se evidencia o seu papel de oferecer fonte alternativa de notícias, uma vez que grande parte dos órgãos de comunicação social dos países africanos estava sob o controlo estatal (Sousa, 1993, p. 10).

Quer através de retransmissores montados em lugares geoestratégicos, quer por via de acordo com as rádios locais, as emissoras internacionais foram crescendo as suas coberturas radiofónicas para África e, simultaneamente, influenciaram as mudanças para a melhoria das políticas internas e reforço dos direitos dos cidadãos. Neste esforço, não se pode descartar a hipótese de que tiveram o papel central em impor através de hegemonia tecnológica as suas culturas e modelos governativos (Archangelo, 2006).

As transmissões de radiodifusão internacional transformaram-se em meios de transmissão de programas sobre as liberdades e direitos humanos aos ouvintes africanos e, posteriormente, transformaram-se no poder influenciador da cultura e da ideia de abertura para a globalização comercial. A política de radiodifusão passava "com frequência mais utilmente por uma impregnação cultural lenta das mentalidades" (Archangelo, 2006; Jeanneney, 1996, p. 264).

Na BBC África e na RFI houveram mudanças significativas nas ideologias e na forma de contar as histórias. As duas estações emissoras começaram por quebrar as barreiras linguísticas. Por exemplo, a BBC conseguiu, até 2009, transmitir em 33 línguas locais, enquanto a rádio France Internationale, demorou muito para abordar a transmissão de informação em línguas africanas, apenas iniciando seus programas em Hausa em 2007 e os de Swahili em 2010. Esta nova política já permitiu à emissora francesa assumir a 
liderança em Níger, onde a BBC foi a rádio internacional mais ouvida em 20 anos. No que lhe concerne, a Deutsche Welle assumiu mudanças em África através da língua Amárico, além de Hausa e Swahili e a VOA passou a transmitir em 10 línguas africanas (Barrot, 2010).

Com base no exposto, fica claro que desde a independência dos países africanos, na década de 6o, as rádios ocidentais em África desenvolveram a teoria de mão dupla: uma influenciando a melhoria dos sistemas de governação e consciencialização das liberdades e direitos humanos e, outra, impondo modelos culturais e abrindo espaços para a globalização comercial, consequentemente, a construção de narrativas de África sob ponto de vista ocidental. Esta foi a perceção da jornalista Hirsch (2012) no seu texto "The west's lazy reporting of Africa".

De acordo com Asekun-Olarinmoye, Esiri, Ogungbamigbe e Balofin (2014) houve duas consequências principais da cobertura tendenciosa dos média ocidentais em África: em primeiro lugar, o modelo de narrativa criou um quadro muito negativo e uma percepção pessimista dos países em desenvolvimento pelos cidadãos das sociedades industrializadas, particularmente aqueles que nunca estiveram no continente africano. Essas pessoas tendem a ver o continente africano como um país sem fronteiras nem identidades. A segunda consequência desta visão pessimista de África é o efeito negativo sobre o investimento estrangeiro direto, pois a cobertura tendenciosa ou negativa de África afeta o fluxo de investimento estrangeiro directo.

O paradoxo do imperialismo cultural das rádios ocidentais, apesar de ter sido concebido com o propósito político, ainda mantém uma carga de imposição cultural na sua programação e informação. Ou seja, detém o controlo sobre o modo pelo qual os factos importantes difundem-se pelo mundo. Além disso, têm outros interesses subjetivos a defender como, por exemplo, ajudar os seus governos a cumprir objetivos políticos, promoção cultural e seus valores nos países africanos.

Nos últimos anos registam-se melhorias das narrativas das rádios internacionais sobre África. Abordagens mais próximas do consenso tentam ocupar espaços nos média internacionais, que tentam destacar a diversidade de programas sobre o continente africano como, por exemplo: programas sobre a diversidade cultural, mercado, religiões, arte, sistemas governativos, música, literatura, etc.

A abordagem dos aspetos positivos de África é notória na Rádio França Internacional $(\mathrm{RFI})$, que privilegia as fontes de informação e jornalísticas oriundas da África. $\mathrm{Na} \mathrm{RFI}$, $60 \%$ da programação é orientada às questões africanas com objetivo de promover proximidade da rádio com a audiência local, internacional e da diáspora africana (Archangelo, 2006). A política de comunicação da RFI deixa dúvida se realmente privilegia a promoção de África. Subtende-se em todos os programas produzidos e transmitidos para África que existe interesse cultural e linguístico bastante expressivo em toda a boa vontade da França em relação às suas ex-colónias.

Outras mudanças ocorrem na BBC África, que apresentam alguns programas radiofónicos feitos por africanos como, por exemplo, Focus on Africa, Network Africa, Fast 
Track e African Performance, nos quais abordam uma diversidade de temas, desde desporto, negócio, arte, literatura e religião. Houve um pequeno recuo de investimento neste campo, devido à contenção de custos com programas internacionais, mas a BBC demonstrou um avanço na produção de narrativas positivas sobre África, chamando interesse da audiência global para ter novas percepções sobre o continente.

Percebe-se nesta discussão que as rádios imperialistas ocidentais tinham uma perceção errada de África. Uma das razões do fraco entendimento de África deve-se à análise dos eventos ou ocorrências africanas sob o prisma ocidental. Outra observação é o facto do grosso número das rádios africanas apresentarem um quadro frágil de sustentabilidade, designadamente, a carência de recursos essenciais para o bom funcionamento dos meios de comunicação social como impressoras, papel, veículos de distribuição e de muitos outros instrumentos indispensáveis à edição e distribuição de jornais (Levingston, 2011).

A presença dos canais internacionais em África deve-se, por um lado, às razões de projecções diplomáticas dos países ocidentais para África. Por outro, constitui para os ouvintes que vivem em países africanos um meio alternativo de informação, cujos regimes se esforçam por controlar os meios de comunicação internos. Ou seja, as ondas de rádio transnacionais permitem que os ouvintes africanos contornem as políticas de censura oficial, dando-lhes acesso às rádios ocidentais, que lhes permite formar sua opinião (Mattelart, 2015).

Em termos gerais, as políticas dos média ocidentais focavam inicialmente nas questões de hegemonia cultural e de civilização, mas nas últimas décadas regista-se um novo quadro de abordagem baseada numa relação consentida caracterizada por inclusão das narrativas africanas nas rádios internacionais, respondendo a uma nova ordem mundial de comunicação equilibrada.

\section{PerCeÇões AFricanas SObre aS RÁdios OCIDENTAIS}

Em março de 2015, um grupo de 159 académicos, escritores e jornalistas de vários países endereçaram uma carta ao produtor executivo do programa Go Minutos da televisão norte-americana CBS, criticando a forma distorcida como os africanos foram apresentados em três reportagens: duas sobre vida selvagem e outra sobre a epidemia de ébola na Libéria. De acordo com o teor da carta, os africanos ficaram limitados ao papel de vítimas passivas ou a vilões brutais, corruptos e incompetentes. Eles foram apresentados como se não tivessem capacidade de ação.

Ngũgĩ wa Thiong'o, um dos grandes escritores africanos, no discurso proferido no dia 25 de maio de 2012 na Universidade do Estado Livre da África do Sul, disse que esta imagem negativa da África é espalhada e intensificada nas imagens de todos os dias no Ocidente, em forma de documentários da televisão para ilustrar a fome, vítimas de ciclone, crimes violentos e guerra étnica (Dersso, 2014).

A visão de Ngũgĩ wa Thiong'o é partilhada pela escritora queniana Nanjala Nyabola, a qual observou que os jornalistas ocidentais continuam a abordar os assuntos africanos 
de forma errada: (a) analisam a realidade em oposição ao Ocidente e não a partir da realidade intrínseca; (b) ao trabalharem em países com a língua diferente da sua necessitam de intérpretes, o que afeta a compreensão do fenómeno. A escritora apontou como solução o emprego de jornalistas locais a reportar, em lugar de serem contratados para assessorar os jornalistas ocidentais (Nyabola, 2014).

Mamdani (2009), um dos principais pensadores críticos e intelectuais de África, criticou no seu livro Saviors and survivors: Darfur, politics, and the war on terror, aqueles que confiam nos média ocidentais para obter informação sobre África. Para o escritor, os média ocidentais chegam a pensar que África é o manancial de informação para alimentar as suas televisões, sobretudo, os conflitos armados, guerras étnicas, doenças contagiosas e outros males, ao invés de construírem narrativas jornalísticas de paz e reconciliação.

Percorrendo profundamente a posição de Mamdani (2009), a hegemonia tecnológica das rádios ocidentais cria nas audiências africanas a ideia de serem os únicos meios fiáveis e credíveis das notícias, em detrimento das rádios locais.

Num outro ângulo de análise, não é verdade que as rádios africanas dependam dos órgãos de comunicação internacionais baseados no Ocidente para divulgar as suas notícias. De acordo com Asante (2013), isto trata-se de uma forma sistemática de inferiorização da África, que faz parte do tecido filosófico e cultural da europeização da África, segundo a qual África não pode relatar as suas próprias histórias. Na verdade, "eles", leiam-se os africanos, são parte do problema, perpetuando e disseminando perspetivas ocidentais, preconceitos e estereótipos (Gathara, 2014).

\section{AS NARRATIVAS AFRICANAS NAS WEB RÁDIOS VIA STREAMING}

A rádio ainda é o meio de comunicação de massa dominante na África com o maior alcance geográfico e as maiores audiências em comparação com a televisão e jornais. Em geral, a rádio está passar por um processo de "radiomorfose" e por um renascimento devido às tecnologias mais acessíveis, uma percepção de que a tecnologia tornou a rádio como um meio bidirecional e que pode ajudar a diminuir a exclusão digital ao fornecer um meio poderoso para a disseminação de informações, especialmente para audiência rural de difícil alcance.

As plataformas dos média sociais e as transmissões das rádios por via streaming abrem um espaço de oportunidade aos africanos para contar as suas histórias em primeira mão, retirando a mediação das rádios internacionais em África e dando-lhes outra visibilidade contada por eles mesmos. Ao mesmo tempo, a web rádio deseja oferecer uma nova perspectiva no campo da informação em comparação com a fornecida pelos meios de comunicação ocidentais.

Há uma redescoberta do rádio no contexto das TIC (tecnologias da informação e comunicação), uma percepção de que a tecnologia streaming está a transformar a rádio em um meio que ajuda a reduzir o fosso digital, fornecendo uma ferramenta poderosa para disseminação de informações para o público com acesso à internet. 
Para Girard (2004), as estações de rádio africanas com sites e que oferecem transmissão via streaming de áudio estão em minoria, mas tendem a aumentar à medida que os custos de largura de banda da internet diminuem gradualmente. O número de pessoas que escuta as webrádios transmitidas em streaming é muito baixo. Mas numa análise profunda, o interesse por tais estações streaming atrai mais a audiência juvenil detentora de dispositivos móveis e com acesso à internet das companhias operadoras de telefonia móvel e da diáspora africana, que constitui uma das principais audiências da webrádio e dos média sociais.

As vantagens das estações de rádio em streaming ainda não são aceites com facilidade, sobretudo nas populações empobrecidas, onde a conexão da internet ainda não é a principal prioridade. No entanto, para muitas estações de rádio, particularmente aquelas que levam a sério a coleta de notícias e reportagens, a internet é um benefício enorme. Agora, notícias internacionais, desporto, previsão do tempo, etc., estão disponíveis quase que instantaneamente.

Os dados da Internet World Stats $2 \mathrm{O}^{2} \mathrm{O}^{2}$, revelam que em África cresceram as taxas de penetração da internet na ordem dos 39,3\% até março de 2020 . Do universo de 4.575.578.718 usuários de internet no mundo, 11,5\% situam-se no continente africano.

A internet no continente africano é tratada como um "artigo de luxo". Quanto ao custo, segundo um levantamento feito pela Cable.co.uk mostrou que de 36 países africanos pesquisados apenas sete países (Egito, Tunísia, Reunião, Argélia, Ilhas Maurício, Marrocos e Mayotte) tinham pacotes que custavam menos que US\$503.

Os média sociais constituem uma plataforma poderosa para criar várias histórias sobre a África, graças à acessibilidade da tecnologia moderna. Por isso, as rádios tradicionais, os blogueiros e comentaristas dos média sociais africanos estão a usar o Facebook, - YouTube e outras plataformas para criar as suas narrativas para alcançar a audiência universal. O exemplo disto é a campanha "The Africa the media never shows you", liderada por jovens africanos, que difundem através de webrádio e "postam" imagens positivas sobre o continente para combater o estereótipo mostrado pelos média ocidentais.

As redes sociais em África estão a capturar as histórias humanas positivas. Elas abrem espaço para contar e partilhar as múltiplas experiências africanas. Esses momentos de alegria, brincadeira, celebração, amor e interação humana criam narrativas de África. Essas novas representações podem desencadear uma viragem na forma de contar as estórias dos africanos, de forma desentermediada.

A taxa de penetração da internet e dos dispositivos móveis, a massificação das redes sociais da internet são elementos que concorrem para a manifestação de narrativas diferentes e multidireccionais sobre o continente africano. Por exemplo, web rádios, blogues, páginas de webnotícias e redes sociais da internet contam estórias, mostram fotografias e vídeos capturados em África pelos africanos na tentativa de formar um retrato mais completo da vida no continente.

\footnotetext{
${ }^{2}$ Disponível em https://www.internetworldstats.com/statsı.htm

${ }_{3}$ Retirado de https://www.cable.co.uk/broadband/pricing/worldwide-comparison/\#regions
} 
As várias vozes africanas nos média sociais podem ser interpretadas como uma tentativa africana de construção dos seus discursos pós-coloniais para contestar as narrativas de descaracterização africana.

No campo dos telemóveis, apesar da maioria da população enfrentar a exclusão digital, os dispositivos móveis smartphones representavam acima de 620 milhões de conexões móveis em setembro de 2011 e prevê que cheguem a 735 milhões no final 2012 (GSMA, 2011). Estas potencialidades tecnológicas constituem uma oportunidade de impulsionar as web rádios africanas para o alcance das audiências globais. Os jornalistas podem anunciar seus números de telefone pelo ar e convidar ouvintes para telefonar ou enviar mensagens com comentários sobre notícias, perguntas, saudações, pedidos de música, etc.

\section{DISCUSSÃo}

Desde a instalação dos emissores das rádios internacionais em África, depois da II Guerra Mundial e da independência dos países africanos, eram claras as políticas do imperialismo ocidental. No entender dos críticos da escola francesa de Comunicação, os estados ocidentais mantinham uma influência ideológica e cultural sobre África, primeiro através da rádio e segundo, através da televisão e indústrias culturais, mais tarde através da estratégia de acordos de cooperação técnica e contrapartidas comerciais para a retransmissão do sinal. Esta última estratégia foi aplicada pela RFI, RTP e BBC quer através dos meios radiofónicos, quer televisivos.

A construção de narrativas ocidentais sobre África, através de transmissão radiofónica, muitas vezes carregada de preconceitos e pessimismo foi uma prática que durou muitos anos, sobretudo, a forma como o continente africano e seus países são descritos no Ocidente, onde a situação africana é avaliada pelas lutas tribais e misérias nos seus países. Uma reflexão realizada no "Fórum de Meios de comunicação social e desenvolvimento" realizado em Uagadugu, Burquina Faso, em setembro de 2008, estabeleceu novos marcos comunicacionais entre o Ocidente e África, num processo que Bourges (1978) designou de "descolonização de informação".

No período a seguir à independência dos países africanos, não eram apenas as rádios ocidentais que eram culpadas pelo imperialismo político e cultural em África. Internamente, as rádios locais da herança colonial transformaram-se em monopólio do Estado, por um lado como instrumento de propaganda política e, por outro, como meio de incentivo ao desenvolvimento social (Agbobli, 2016).

Percebe-se, depois do fórum de Burquina Faso de 2008, subsequentes mudanças de modelo de comunicação das rádios ocidentais em África, graças às novas políticas de cooperação e informativa que se foram estabelecendo entre África e o Ocidente, onde a BBC África, RFI e a Deutsche Welle mostraram mudanças significativas ao incorporar as línguas africanas nas suas emissões informativas.

Interpretando Jeanneney (1996), Archangelo (2006) e Hirsch (2012), nos períodos subsequentes ao fórum de Burquina Faso, as rádios ocidentais em África tornaram-se 
um sistema influenciador de políticas democráticas, promotores dos direitos humanos e, simultaneamente, operavam no sentido de converter as audiências em massa numa crítica interna.

No início, a presença das grandes cadeias de rádios ocidentais no continente africano impunha uma espécie de hegemonia mediática sobre os média locais, bem como o poder avassalador na (re)interpretação dos factos, assim como na influência decisiva da opinião pública e, às vezes, nas interferências políticas.

Nas últimas décadas, embora se registem melhorias no novo quadro de abordagem sobre África, no qual busca introduzir formatos de inclusão das narrativas africanas nos média ocidentais, revertendo o antigo cenário de narrativas únicas, porém, a cobertura negativa do continente persiste nalgumas rádios internacionais, cenário que pode ser ultrapassado por países africanos através de medidas mais práticas para contar as suas próprias histórias ao mundo exterior.

\section{Conclusão}

O papel das rádios internacionais em África é um assunto de grande interesse africano quer como memória histórica, quer como objecto de estudo que precisa ser avaliado antes que as memórias se apaguem.

A reflexão permitiu-nos trazer novos caminhos para a análise histórica das rádios internacionais em África em uma estrutura multidisciplinar que liga as Ciências da Comunicação, História e Política. Outras abordagens mais específicas centradas, por exemplo, nos objetivos de criação de cada rádio internacional, na distribuição geográfica das rádios em África e tipologia de narrativas, poderiam permitir-nos complementar os resultados do estudo e aproximar a realidade e, assim, contribuir para o debate holístico em torno das narrativas das rádios ocidentais em África.

O questionamento sobre as narrativas das rádios ocidentais sobre África no períodos pós-independência e que perspectivas para o futuro da rádio em África? A resposta é encontrada na discussão de resultados, descobriu-se que elas retrataram através de três tipos de discursos e ideologias diferentes em três momentos históricos: o primeiro, desenvolvimento de uma narrativa para o acompanhamento da política colonial, manutenção e transmissão da cultura e civilização ocidental; o segundo, narrativas de guerras ideológicas durante o período da Guerra Fria, altura da massificação das rádios ocidentais no continente africano; e o terceiro, interesse, depois da Guerra Fria, era do desenvolvimento da cooperação e de produção de novas narrativas focalizadas em regiões de conflitos em África.

O "Fórum de Meios de comunicação social e desenvolvimento" realizado em Uagadugu, foi o principal marco de mudança das narrativas das rádios ocidentais em relação à África. A partir do qual começou o processo de "descolonização de informação", iniciado pelas rádios BBC, RFI, Deutsche Welle e VOA ao incorporar nas suas emissões as línguas africanas para que os africanos tivessem a oportunidade de apresentar as suas próprias narrativas e mudar o imaginário social do Ocidente em relação à África. 
É preciso pensar que a "descolonização da informação" não libertou os países africanos do imperialismo das rádios ocidentais, enquanto internamente as rádios eram tomadas por alguns regimes políticos como meio de propaganda política.

Apesar de todas as vicissitudes históricas das rádios em África, hoje em dias elas caminham para uma maior autonomia de produção de conteúdos locais, dentro do quadro da liberdade de imprensa e de expressão.

Quanto às perspectivas futuras para a rádio em África, tanto quanto pode ser previsto, a FM parece ainda ter um futuro sólido na África. A webrádio e a digital audio broadcasting (DAB) poderão ser adotadas por emissoras africanas num futuro próximo, dada a queda de preços da internet e a massificação de smartphones com rádio FM incorporada.

\section{REFERÊNCIAS}

Agbobli, C. (2016). Démocratie, communication et changement en Afrique subsaharienne francophone. REFSICOM, (2). Retirado de http://www.refsicom.org/135

Amin, S. (2015, 05 de junho). De Bandung (1955) a 2015: velhos e novos desafios. Carta Maior. Retirado de https://www.cartamaior.com.br/?/Editoria/Pelo-Mundo/ De-Bandung-1955-a-2015-velho-e-novos-desafios/6/33668

Archangelo, F. A. B. (2006). Redes internacionais em estações locais caso RFI África. Retirado de http://www. comtec.pro.br/prod/artigos/archangelo_afr_cpc2006.pdf

Asante, M. (2013). The western media and the falsification of Africa: complications of value and evaluation. China Media Research, 9(2), 64-70.

Asekun-Olarinmoye, O. S., Esiri, M. J., Ogungbamigbe, O. O. \& Balofin, A. (2014). The impact of international broadcasting on Africa. Developing Country Studies, 4(4), 78-84. Retirado de https://core.ac.uk/ download/pdf/234681533.pdf

Barrot, P. (2010, 20 de outubro). Les radios internationales en Afrique. La Revue des Médias. Retirado de https://larevuedesmedias.ina.fr/les-radios-internationales-en-afrique

Biney, A. (1997). The western media and Africa: issues of information and images. Journal of International Affairs, 1996/1997(2), 1-2. Retirado de http://www.inquiriesjournal.com/a?id=1156

Bourges, H. (1978). Décoloniser l'information. Paris: Éditions Cana.

Carvalho, A. (1994, julho). Cooperação Portugal-PALOP no domínio da comunicação social. Comunicação apresentada no III Congresso Luso-Afro-Brasileiro de Ciências Sociais, Lisboa. Retirado de http:// repositorium.sdum.uminho.pt/bitstream/1822/2815/1/acarvalho_IIILusoAfroBr_1994.pdf

Dersso, S. (2014, 06 de Março). Reporting Africa: in defence of a critical debate. Aljazeera. Retirado de https://www.aljazeera.com/opinions/2014/3/6/reporting-africa-in-defence-of-a-critical-debate

Gathara, P. (2014, 24 de janeiro). If western journalists get Africa wrong, who gets it right?. The Guardian. Retirado de https://www.theguardian.com/world/2014/jan/24/africa-media-who-gets-right

Girard, B. (2004). La radio e internet: mezclar los medios para cerrar la brecha digital. In B. Girard (Ed.), Secretos a voces: radio, NTICs e interactividad (pp. 5-22). Roma: Organización de las Naciones Unidas para la Agricultura y la Alimentación. Retirado de http://www.fao.org/3/a-y4721s.pdf 
Goutier, H. (2008, dezembro). Os debates de Uagadugu. Le Courrier, pp. 3-4.

Groppo, B. (2008). O comunismo na história do século XX. Lua Nova, 115-141. https://doi.org/10.1590/ So102-64452008000300007

GSMA, Global System for Mobile Communications Association. (2011). African mobile observatory 2011: driving economic and social development through mobile services report. Retirado de https://www.gsma.com/ spectrum/wp-content/uploads/2011/12/Africa-Mobile-Observatory-2011.pdf

Hirsch, A. (2012, 15 de abril). The west's lazy reporting of Africa. The Guardian. Retirado de https://www. theguardian.com/commentisfree/2012/apr/15/west-lazy-reporting-africa

Ilboudo, J. P. (2014, fevereiro). Les etapes d'implantation de la radio en Afrique noire. Comunicação apresentada no Dia Mundial da Rádio, Dakar. Retirado de http://www.unesco.org/new/fileadmin/MULTIMEDIA/ FIELD/Dakar/pdf/ConferencesurlaradioenAfriqueNoire130214.pdf

Jeanneney, J. (1996). Uma história da comunicação social. Lisboa: Editora Terramar.

Joanguete, C. (2010, julho). O delete da memória cultural na contemporaneidade africana. Comunicação apresentada no Simpósio Nacional de História-UNIRIO, Rio de Janeiro. Retirado de http://www. encontro2010.rj.anpuh.org/resources/anais/8/1272923398_ARQUIVO_Delitedamemoriacultural.pdf

Jordão, A. (2009). Som, audiência e arquivo: a RDP África como case study. Dissertação de Mestrado, Instituto Superior de Ciências do Trabalho e da Empresa, Lisboa, Portugal. Retirado de http://hdl.handle. net/10071/1893

Landau, J. (2012). Le passé de l'Afrique à la radio, mémoire d'un continent (RFI): pour une histoire de la coopération radiophonique franco-africaine à travers une émission de 1964 à nos jours. Dissertação de Mestrado, Université Paris 1 Panthéon-Sorbonne, Paris, França. Retirado de https://dumas.ccsd.cnrs. fr/dumas-00839173/document

Levingston, S. (2011). A evolução dos sistemas de informação em África: um caminho para a segurança e a estabilidade. Washington: Centro de Estudos Estratégicos de África.

Mamdani, M. (2009). Saviors and survivors: darfur, politics, and the war on terror. Nova lorque: Pantheon Books.

Mattelart, A. \& Mattelart, M. (1997). História das teorias da comunicação. Lisboa: Editora Campo das Letras.

Mattelart, T. (2015, 25 de junho). L'Afrique subsaharienne au défi des médias internationaux. La Revue des Médias. Retirado de https://larevuedesmedias.ina.fr/ lafrique-subsaharienne-au-defi-des-medias-internationaux

Myers, M. (2008). Radio and development in Africa: a concept paper. International Development Research Centre (IDRC). Retirado de https://assets.publishing.service.gov.uk/media/57ao8b3ce5274a31eooooa5c/ Radio_and_Development_in_Africa_concept_paper.pdf

Nyabola, N. (2014, O2 de janeiro). Why do western media get Africa wrong?. Aljazeera. Retirado de https:// www.aljazeera.com/opinions/2014/1/2/why-do-western-media-get-africa-wrong/

Perret, T. (2010). L'Afrique à l'écoute: la France, l'Afrique et la radio mondiale. Cahiers d'Études Africaines, 198199-200, 1003-1032. https://doi.org/10.4000/etudesafricaines.16448

Power, M. (2000). Aqui Lourenço Marques!! Radio colonization and cultural identity in colonial Mozambique, 1932-74. Journal of Historical Geography, 26(4), 605-628. https://doi.org/10.1006/jhge.2000.0240 
Silva, M.(2009). A imagem de África na imprensa europeia: o caso da cimeira UE-

África em dezembro de 2007. Retirado de https://infoeuropa.eurocid.pt/

opac/?func=short-sort\&set_number=003737\&sort_option=03---A

Sousa, H. (1993). BBC nos PALOP's: análise do significado político. Risco, 20, 1-14. Retirado de http:// repositorium.sdum.uminho.pt/bitstream/1822/2706/1/helenasousa_BBCPALOPs_1993.Pdf

Trevor-Roper, H. R. (1969). The past and the present: History and Sociology. Past \& Present, 42(1), 3-17. https://doi.org/10.1093/past/42.1.3

\section{NOTA BIOGRÁFICA}

Celestino Joanguete é doutor em Ciências da Comunicação pela Universidade do Minho, Portugal. É pesquisador em Média e Jornalismo na Escola de Comunicação e Artes da Universidade Eduardo Mondlane. É membro da Organization for Social Science Research in Eastern and Southern Africa (OSSREA) e membro da The Association for Education in Journalism and Mass Communication (AEJMC).

ORCID: http://orcid.org/o0oo-0003-0289-8937

Email: celestino.joanguete@gmail.com

Morada: Escola de Comunicação e Artes, Universidade Eduardo Mondlane, C.P. 257 Maputo, Moçambique

Submetido: 12/02/2020

Aceite: 08/09/2020 